\title{
Commentary: Are we closer than we think to a customizable, endovascular total arch?
}

\author{
Joshua C. Grimm, MD, and Wilson Y. Szeto, MD
}

From the Division of Cardiovascular Surgery, University of Pennsylvania School of Medicine, Philadelphia, Pa. Disclosures: Dr Szeto is an investigator and speaker for Terumo Aortic, an investigator for W. L. Gore, and an investigator for Medtronic. Dr Grimm has nothing to disclose with regard to commercial support.

Received for publication July 30, 2019; accepted for publication July 31, 2019; available ahead of print Sept 5, 2019.

Address for reprints: Wilson Y. Szeto, MD, 51 N 39th St, Heart and Vascular Pavilion, Suite 2A, Philadelphia, PA 19104 (E-mail: wilson.szeto@pennmedicine.upenn.edu).

J Thorac Cardiovasc Surg 2020;160:640

$0022-5223 / \$ 36.00$

Copyright (c) 2019 by The American Association for Thoracic Surgery

https://doi.org/10.1016/j.jtcvs.2019.07.124

In this issue of The Journal of Thoracic and Cardiovascular Surgery, Kuo and colleagues ${ }^{1}$ present their innovative technique in the endovascular management of aortic arch pathology with on-the-table, handmade, fenestrated endografts. The topic is timely, because the minimally invasive management of the thoracic aorta is a rapidly evolving field requiring novel approaches to face an increasingly challenging cohort of high-risk patients.

In their series of 13 cases, Kuo and colleagues ${ }^{1}$ describe the surgical considerations, patient selection, and shortterm outcomes of complete arch reconstruction with preservation of all supra-aortic branches. This zone 0 platform is extremely nuanced, and Kuo and colleagues ${ }^{1}$ are forthright in its selective application in patients at the greatest surgical and anesthetic risk, including those with excessive comorbid burden and complex, reoperative scenarios. With regard to technical planning and execution, Kuo and colleagues ${ }^{1}$ rely on an intraoperative aortogram to determine the appropriate stent size and to delineate arch vessel relationships. Once these measurements have been satisfied, the fenestrations are created and reinforced with a micropuncture wire sutured around the circumference of each orifice. The device is then sheathed and aligned according to the location of the innominate artery. The use of bridging grafts to reinforce the main body and to prevent tear propagation is based on the proximity of the aortopathy to the origin of the branch vessels. Despite the inclusion of patients at high, and perhaps prohibitive, risk, the outcomes were largely favorable. There were no in-hospital deaths, 3 late deaths, and no reinterventions on the proximal stent graft.

The ability to customize a complete endovascular option in real time to mitigate a variety of arch pathologies addresses many of the limitations of current stent technology. Although parallel and branched endografts have been used in the thoracic aorta with variable success, their universal applicability is limited by concerns regarding endoleak and stroke, as well as availability on an emergency basis. . $^{2,3}$

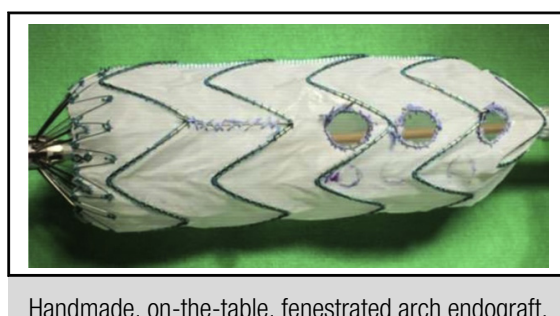

Handmade, on-the-table, fenestrated arch endograft.

\section{Central Message}

Endovascular options for acute management of the aortic arch are limited. The authors present a novel technique of on-the-table fenestration to produce a fully customizable arch endograft.

See Article page 629.

One must, however, temper enthusiasm before abandoning the current standard of open total arch replacement. With continued improvements in cerebral protection and enhancements in neuromonitoring, there has been a reduction in overall morbidity and mortality. ${ }^{4}$ Moreover, the anatomic constraint of requiring an ascending aortic diameter of less than $42 \mathrm{~mm}$ to ensure an adequate seal limits the use of this fenestrated device if an aneurysmal proximal segment is present. Lastly, the need for a repeat thoracic endovascular aortic repair with distal extension in nearly half of the patients, as reported by Kuo and colleagues, ${ }^{1}$ is significant. That having been said, we commend the ingenuity of Kuo and colleagues ${ }^{1}$ and firmly believe that cardiac surgeons must continue to devise and implement new strategies to minimize the impact of intervention on the thoracic aorta.

\section{References}

1. Kuo HS, Huang JH, Chen JS. Handmade fenestrated stent grafts to preserve all supra-aortic branches in thoracic endovascular aortic repair. J Thorac Cardiovasc Surg. 2020;160:629-39.e1.

2. Moulakakis GK, Mylonas SN, Dalainas I, Sfyroeras GS, Markatis F, Kotsis T, et al. The chimney-graft technique for preserving supra-aortic branches: a review. Ann Cardiothorac Surg. 2013;2:339-46.

3. Czerny M, Rylski B, Morlock J, Schröfel H, Beyersdorf F, Saint Lebes B, et al. Orthotopic branched endovascular aortic arch repair in patients who cannot undergo classical surgery. Eur J Cardiothorac Surg. 2018;53:1007-12.

4. Settepani F, Cappai A, Basciu A, Barbone A, Tarelli G. Outcome of open total arch replacement in the modern era. J Vasc Surg. 2016;63:537-45. 